\title{
Reliability of cerebral oximeter in non-invasive diagnosis and follow-up of hypercapnia
}

\author{
Seher Erdoğan, Arzu Oto, Mehmet Boşnak \\ Division of Pediatric Critical Care, Department of Pediatrics, Gaziantep University Faculty of Medicine, Gaziantep, Turkey. \\ E-mail: seher70@gmail.com \\ Received: 22nd April 2016, Revised: 1st September 2016, Accepted: 10th October 2016
}

SUMMARY: Erdoğan S, Oto A, Boşnak M. Reliability of cerebral oximeter in non-invasive diagnosis and follow-up of hypercapnia. Turk J Pediatr 2016; 58: 389-394.

In this study, aimed to evaluate the sensitivity and specificity of cerebral oximetry and EtCO2 values in non-invasive diagnosis and monitoring of hypercapnia. This study enrolled pediatric patients admitted to and mechanically ventilated at the Pediatric Intensive Care Unit of Gaziantep University Faculty of Medicine Hospital between January 2014 and January 2015. Patients' age, gender, diagnosis, ventilatory parameters, a measured of the mean end-tidal carbon dioxide value stream method, and the simultaneously monitored arterial blood gas $\mathrm{PaCO}_{2}$ level and near infrared spectroscopy device (NIRS) measurements were recorded. The mean age of patients was 61 months (min 4-max 193), and there were $8(53.4 \%)$ female and 7 (46.6\%) male subjects. A significant correlation was found between $\mathrm{PCO}_{2}$ and $\mathrm{NIRS}, \mathrm{PCO}_{2}$ and $\mathrm{EtCO}_{2}$ $(\mathrm{r}=0.571, \mathrm{p}<0.001)$. There was a significant positive correlation between $\mathrm{EtCO}_{2}$ and NIRS $(\mathrm{r}=0.479, \mathrm{p}<0.001)$. NIRS levels were significantly higher $(\mathrm{p}<0.001)$ in the group with $\mathrm{pCO}_{2}>45 ; \mathrm{EtCO}_{2}>40$ and $\mathrm{pH}<7.35$, compared to the group with $\mathrm{PCO}_{2}<45 \mathrm{EtCO}_{2}<40$ and $\mathrm{ph} \geq 7.35$. The best cut-off point for NIRS to distinguish the groups with $\mathrm{PCO}_{2}>45$ with $\mathrm{PCO}_{2}<45$ was 80.5 , with a sensitivity of $65.3 \%$, specificity of $84.3 \%$, and positive and negative predictive values of $81.9 \%$ and $69.1 \%$, respectively. The best cut-off point for NIRS to distinguish the groups with $\mathrm{EtCO}_{2}>40$ and $\mathrm{EtCO}_{2}<40$ was 81 , with a sensitivity of $62.2 \%$, specificity $77.9 \%$, and positive and negative predictive values of $61.2 \%$ and $72.3 \%$, respectively. As for $\mathrm{pH}<7.35$ and $\mathrm{PaCO}_{2}>45$, while sensitivity of $\mathrm{EtCO}_{2}$ (at a cut-off point of 40) was $64.9 \%$; the sensitivity of NIRS (at a cut-off point of 80.5) was $28.1 \%$, with $\mathrm{EtCO}_{2}$ being significantly more sensitive than NIRS $(p<0.001)$. The results of the present study suggest that NIRS values of above 80 should alert clinicians for hypercapnia associated with increased cerebral blood flow.

Key words: end-tidal carbon dioxide, hypercapnia, near infrared spectroscope.

Hypercarbia results in cerebral vasodilation and increases the cerebral blood flow, a phenomenon termed as the $\mathrm{CO}_{2}$ cerebrovascular reactivity ${ }^{1}$. Intracranial pressure increases in hypercarbia, which can cause a decrease in cerebral perfusion pressure in patients with significant neurological damage ${ }^{2}$. Although there are individual differences, every $1 \mathrm{mmHg}$ increase in $\mathrm{PaCO}_{2}$ causes an increase in cerebral blood flow of $3 \%$ to $5 \%$. Hypercarbia is also known to lower seizure threshold ${ }^{3,4}$. By virtue of its systemic vasodilatory action, hypercapnia may cause hypotension especially in hypovolemic patients, and it may worsen tissue injury in injured lungs by imparing wound healing and, augmenting inflammation ${ }^{5}$. Animal experiments have shown that hypercapnia stimulates the secretion of gastric hydrogen ions and increases the incidence of gastrointestinal bleeding ${ }^{6}$. Tateyama et al. $^{7}$ showed in dogs that hypercapnia formed by adding $10 \%$ carbon dioxide to the breathing gas after normocapniac ventilation, increased cardiac lactate/pyruvate ratio coronary blood flow, and myocardial tissue oxygenation while it impaired myocardial aerobic metabolism. 
Maintaining normocapnia and normoxemia is the main goal unless indicated otherwise in patients undergoing mechanical ventilation; with the early diagnosis of hypercapnia and taking the necessary measures being a great importance in critically ill patients.

Monitoring of end-tidal carbon dioxide $\left(\mathrm{EtCO}_{2}\right)$ is an important component of monitorization of critically ill patients in anaesthesiology and pediatric intensive care units as well as in the emergency department. Normal $\mathrm{EtCO}_{2}$ is $38 \pm$ $4 \mathrm{mmHg}$. This level is closely correlated with $\mathrm{PaCO}_{2}$ level and is lower than that by about $3.5 \mathrm{mmHg}^{8}$.

The near infrared spectroscopy device (NIRS) that has been used in clinics in recent years can show instant responses in cerebral oxygenation. NIRS is an optical method monitoring primarily regional oxygenation of the brain. The method is based on the Beer-Lambert law for cerebral monitoring from the forehead. An oximeter probe measures concentrations of different wavelengths of light waves in the neck in the frontal cortex [650-850 nm, oxyhemoglobin $(810 \mathrm{~nm})$ and deoxyhemoglobin $(730 \mathrm{~nm})]$ through a cross-sectional tissue. INVOS used as one of the first examples of NIRS calculates regional saturation using two wavelengths in brain or the relevant tissue and measures both oxyhemoglobin and deoxyhemoglobin concentrations, giving a value defined as the regional oxygen saturation index $\left(\mathrm{rSO}_{2}\right.$ index $=$ oksiHb/deoksiHb+oksiHb). $\mathrm{rSO}_{2}$ can be calculated without being connected to the pulse and can rapidly change in response to cerebral ischemia. From this standpoint, studies with healthy young adults and children have shown that the average cerebral $\mathrm{rSO}_{2}$ is $70 \%$, with reductions down to below $40-50 \%$ or $20 \%$ from baseline being reported as an indicator of hypoxic-ischemic neuronal damage ${ }^{9-11}$.
In the present study, we aimed to evaluate the sensitivity and specificity of cerebral oximetry and $\mathrm{EtCO}_{2}$ values in non-invasive diagnosis and monitoring of hypercapnia.

\section{Material and Methods}

After the ethics committee approval, this study enrolled children aged between 1 month and 17 years who were admitted to a 7-bed pediatric intensive care unit (PICU) of a tertiary university hospital and received mechanical ventilation between January 2014 and January 2015. The patients were not intentionally subjected to hypoventilation, and the NIRS levels of patients with elevated EtCO2 levels and hypercarbia in arterial blood gas analysis were recorded. Those with a preliminary or definitive diagnosis of ICP (intracranial pressure increase syndrome), those with increasing ICP levels during monitoring, and those that had congenital heart disease or metabolic acidosis were excluded from the study. Patients' age, sex, comorbidities, mechanical ventilation mode, and mortality scoring were recorded.

$\mathrm{EtCO}_{2}$ values were measured continuously with the Nihon Kohden BSM-4114 intensive care monitor using an invasive infrared spectroscopy and mean-stream methods. $\mathrm{rSO}_{2}$ values were measured with a somatic-cerebral oximeter (INVOS 5100C, Somanetics). The NIRS probe was applied to the forehead, just above the eyebrows. To assess acid-base and to determine respiratory balance, partial pressures of arterial blood oxygen $\left(\mathrm{PaO}_{2}\right)$ and carbon dioxide $\left(\mathrm{PaCO}_{2}\right)$ were measured with arterial blood gas analysis. Patients with metabolic acidosis were excluded from the study protocol.

\section{Statistical analysis}

Data analysis was done with SPSS for Windows 11.5 software package. The distribution of

Table I. Diagnosis of Patients

\begin{tabular}{lcc}
\hline Diagnosis & The number of cases $(\mathrm{n})$ & Percentage $(\%)$ \\
\hline Kidney diseases & 6 & 40 \\
Respiratory disorders & 4 & 26.6 \\
Nervous system diseases & 3 & 20 \\
Hemato-oncological diseases & 1 & 6.7 \\
Scorpion stings & 1 & 6.7 \\
Total & 15 & 100 \\
\hline
\end{tabular}


Table II. NIRS measurements according to $\mathrm{PaCO}_{2}, \mathrm{EtCO}_{2}$ and $\mathrm{pH}$

\begin{tabular}{lccc}
\hline \multicolumn{1}{l}{ Variables } & $\mathrm{n}$ & $\begin{array}{c}\text { The mean } \\
(\text { min-max })\end{array}$ & $\mathrm{P}_{\text {value }}^{+}$ \\
\hline \multicolumn{1}{c}{$\mathrm{PaCO}_{2}$} & & & $<0.001$ \\
$>45$ & 173 & $72(46-99)$ & \\
$<45$ & 159 & & $<0.001$ \\
$\mathrm{EtCO}_{2}$ & & $83(47-98)$ & \\
$>40$ & 119 & $74(46-99)$ & \\
$<40$ & 213 & $72(46)$ & \\
\hline
\end{tabular}

+ Mann Whitney U test $\mathrm{PaCO}_{2}$ : Partial pressure of arterial carbon dioxide $\mathrm{EtCO}_{2}$ : End-tidal carbondioxide

quantitative variables was investigated using Kolmogorov-Smirnov or Shapiro-Wilk test. Descriptive statistics included mean \pm standard deviation for continuous variables and number and percentage (\%) of for nominal variables.

The significance of the difference of the median values of pairs of groups was analysed with the Mann-Whitney U test. Spearman's correlation test was used to test the significance of the relationship between continuous variables. Nominal variables were evaluated with Pearson's Chi-square or McNemar test.

Whether NIRS value was a significant marker that differentiated groups with $\mathrm{PCO}_{2}>45$ and $\mathrm{PCO}_{2}<45$ and $\mathrm{EtCO}_{2}>40$ with $\mathrm{EtCO}_{2}<40$ was explored using $95 \%$ confidence intervals and area under ROC curve. When a significant area under the curve was obtained, the maximum possible sum of the sensitivity and specificity levels was considered the best cut-off point. Then, the sensitivity, specificity, positive and negative predictive values of the best NIRS cut-off points were calculated. A p-value of less than 0.05 was considered statistically significant.

\section{Results}

The mean age of the patients was 61 (4- 193) months. There were 8 (53.4\%) female subjects and $7(46.6 \%)$ male subjects. All patients were provided with respiratory support by mechanical ventilation in SIMV-PS (pressure support-synchronised intermittent mandatory ventilation) mode. A mean PIP of $22 \mathrm{~cm} \mathrm{H}_{2} \mathrm{O}$ (min 12-max 39), a mean PEEP of $7 \mathrm{~cm}$ (min 1-max 15), a mean $\mathrm{FiO}_{2}$ of 0.6 (min 0.3- max 1 ), and a mean frequency of $25 / \mathrm{min}$ (min 14 max 60) were applied. Nephrological disorders constituted $40 \%$ of the patients' diseases, followed by respiratory system diseases and

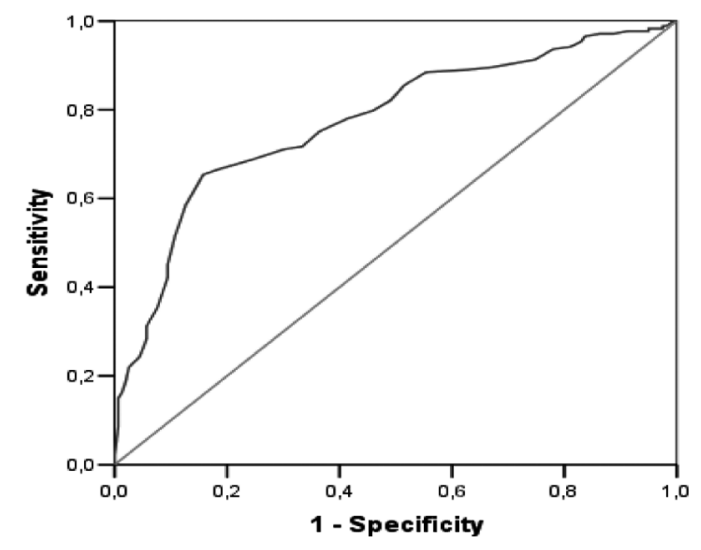

Fig. 1. The ROC curve regarding NIRS measurements to differentiate groups with $\mathrm{pCO}_{2}>45$ and $\mathrm{pCO}_{2}<45$

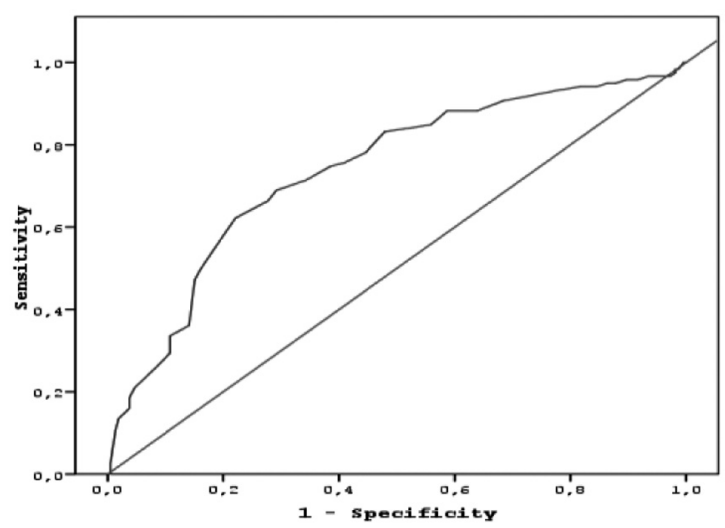

Fig. 2. The ROC curve regarding NIRS measurements to differentiate groups with $\mathrm{EtCO}_{2}>40$ and $\mathrm{EtCO}_{2}<40$

neurological diseases. Diagnoses of the patients were presented on Table I.

A significant correlation was found between $\mathrm{PCO}_{2}$ and NIRS, and between $\mathrm{PCO}_{2}$ and $\mathrm{EtCO}_{2}$ $(\mathrm{r}=0.571, \mathrm{p}<0.001)$. A significant positive correlation was also detected between $\mathrm{EtCO}_{2}$ and NIRS ( $\mathrm{r}=0.479, \mathrm{p}<0.001)$.

NIRS levels were significantly higher in the 
Table III. The Distribution of $\mathrm{PaCO}_{2}$ and $\mathrm{EtCO}_{2}$ Measurements

\begin{tabular}{lccc}
\hline & $\mathrm{PaCO}_{2}<45$ & $\mathrm{PaCO}_{2}>45$ & Total \\
\hline $\mathrm{EtCO}_{2}<40$ & $132(39.8 \%)$ & $81(35.2 \%)$ & $213(81.6 \%)$ \\
$\mathrm{EtCO}_{2}>40$ & $24(7.2 \%)$ & $95(28.6 \%)$ & $119(18.4 \%)$ \\
Total & $156(47.0 \%)$ & $176(53.0 \%)$ & $332(100 \%)$ \\
\hline
\end{tabular}

group with $\mathrm{PCO}_{2}>45, \mathrm{EtCO}_{2}>40$ and $\mathrm{pH}<7.35$ compared to the group that had $\mathrm{PCO}_{2}<45$, $\mathrm{EtCO}_{2}<40$, and $\mathrm{pH} \geq 7.35$ (p <0.001) (Table II).

The mean NIRS value was 79 (min 46-max 99) when $\mathrm{pCO}_{2}$ was $>35$ and $68(\min 55, \max$ 86) when $\mathrm{pCO}_{2}$ was $<35(\mathrm{p}<0.001)$.

The area under the ROC curve for NIRS was able to reliably distinguish the groups with $\mathrm{PaCO}_{2}>45$ and $\mathrm{PaCO} 2<40$ (area under the curve: $0.775,95 \%$ confidence interval: $0.724-$ 0.825, $\mathrm{p}<0.001$ ) (Fig.1). To distinguish the groups with $\mathrm{pCO}_{2}>45$ with $\mathrm{PCO}_{2}<45,80.5$ was the best cut-off point for NIRS, having a sensitivity of $65.3 \%$, specificity of $84.3 \%$, and positive and negative predictive values of $81.9 \%$ and $69.1 \%$, respectively.

The area under the ROC curve for NIRS could reliably distinguish the groups with $\mathrm{EtCO}_{2}>40$ and $\mathrm{EtCO}_{2}<40$ (area under the curve: 0.737, $95 \%$ confidence interval: from 0.687 to 0.784 , p <0.001) (Fig. 2). The best cut-off point for measurements to distinguish between the groups with $\mathrm{EtCO}_{2}>40$ and $\mathrm{EtCO}_{2}<40$ was 81 , having a sensitivity of $62.2 \%$, specificity of $77.9 \%$, and positive and negative predictive values of $61.2 \%$ and $72.3 \%$, respectively.

While the proportion of patients with $\mathrm{PaCO}_{2}>$ 45 was $53 \%$, those with $\mathrm{EtCO}_{2}>40$ was $28.6 \%$, with the ratio of patients with $\mathrm{pCO}_{2}>45$ being significantly higher than the proportion of those with $\mathrm{EtCO}_{2}>40(\mathrm{P}<0.001)$. There was a statistically significant, albeit a very low level concordance between the distribution of $\mathrm{PaCO}_{2}$ and $\mathrm{EtCO}_{2}$ levels (Kappa 0.378 and $\mathrm{p}<0.001)$. The distributions of $\mathrm{PaCO}_{2}$ and
$\mathrm{EtCO}_{2}$ measurements were shown on Table III. In patients with $\mathrm{PaCO}_{2}>45$; the median $\mathrm{EtCO}_{2}$ level was 40 (max 70, min-21), while the median $\mathrm{EtCO}_{2}$ level was 35 in patients with $\mathrm{PaCO}_{2}<45(\min 15, \max 50)$, with the median $\mathrm{EtCO}_{2}$ level being significantly higher in those with $\mathrm{PaCO}_{2}>45(\mathrm{p}<0.001)$.

As for $\mathrm{pH}<7.35$ and $\mathrm{PaCO}_{2}>45$, while the sensitivity of $\mathrm{EtCO}_{2}$ (at a cut-off point of 40) was $64.9 \%$, NIRS had a sensitivity (at a cut-off point of 80.5 ) of $28.1 \%$, with $\mathrm{EtCO}_{2}$ being significantly more sensitive than NIRS ( $\mathrm{p}$ $<0.001$ ). NIRS measurement results in relation to to $\mathrm{PaCO}_{2}$ and $\mathrm{pH}$ levels were presented on Table IV.

\section{Discussion}

The difference between $\mathrm{EtCO}_{2}$ and $\mathrm{PaCO}_{2}$ is a result of alveolar dead space, and its normal value is between 3 and $5 \mathrm{mmHg}$. Decrease in lung perfusion (air embolism, position changes, decreased cardiac output, reduced blood pressure), increases alveolar dead space, diluting exhaled carbon dioxide, and reducing $\mathrm{EtCO}_{2}$. EtCO $\mathrm{tCO}_{2}$ increases when carbon dioxide production is increased such as sepsis, malignant hyperthermia, and in cases where its elimination is limited by reduced alveolar ventilation. The return of spontaneous circulation during cardiopulmonary resuscitation quickly raises $\mathrm{EtCO}_{2}{ }^{12,13}$.

In a study of 32 mechanically ventilated newborns dated 2008, there was a good correlation between mainstream $\mathrm{EtCO}_{2}$ and $\mathrm{PaCO}_{2}$. Whereas this correlation was impared in

Table IV. NIRS Measurements According to $\mathrm{PaCO}_{2}$ and $\mathrm{pH}$ Level

\begin{tabular}{lccc}
\hline & $\mathrm{PaCO}_{2}<45$ & $\mathrm{PaCO}_{2}>45$ & $\mathrm{p}$-value $\dagger$ \\
\hline $\mathrm{pH}<7.35$ & $76(62-88)$ & $85(47-96)$ & 0.007 \\
$\mathrm{ph} \geq 7.35$ & $71(46-95)$ & $81(61-99)$ & $<0.001$ \\
p-value & 0.117 & $<0.001$ & \\
\hline
\end{tabular}

Comparisons made between the $\mathrm{pCO} 2$ level when $\dagger \mathrm{pH}$ levels are kept constant

Comparisons made between the $\mathrm{pH}$ levels when $\$ \mathrm{PaCO}_{2}$ levels are kept constant (Mann-Whitney $\mathrm{U}$ test) 
those with pulmonary disease, it was restorated by the application of surfactant ${ }^{14}$. Several other studies conducted at neonatal intensive care units also supported this result ${ }^{15}, 16$.

In a study conducted by McDonald et al. ${ }^{17}$ in mechanically ventilated pediatric patients, the difference between $\mathrm{EtCO}_{2}$ and $\mathrm{PaCO}_{2}$ was $\leq 5$ $\mathrm{mm} \mathrm{Hg}$ in $54 \%$ of patients and $\leq 10 \mathrm{mmHg}$ in $80 \%$. Furthermore, the gap widened as the duration of mechanical ventilation was increased.

$\mathrm{Raz}$ et al. ${ }^{18}$ reported that $\mathrm{EtCO}_{2}$ accurately reflected $\mathrm{PaCO}_{2}$ and there was a statistically significant correlation between mean $\mathrm{EtCO}_{2}$ and $\mathrm{PaCO}_{2}$ (in SIMV mode $\mathrm{r}: 0.893, \mathrm{p}<0.0001$; in CPAP mode $\mathrm{r}$ : 0841 , $\mathrm{p}<0.0001$; in T-Tubes $\mathrm{r}: 0.923, \mathrm{p}<0.0001)$.

In a study comprising children on mechanical ventilation conducted by Mehta et al. ${ }^{19}, \mathrm{EtCO}_{2}$ showed an excellent correlation with $\mathrm{PaCO}_{2}$ (n $=150, \mathrm{r}: 0.914)$, although it was no longer the case when P / F <200. Similarly, Bath et al. ${ }^{20}$ reported that this correlation was impared in case of lung pathologies such as hyaline membrane disease or meconium aspiration.

De Waal et al. ${ }^{21}$ investigated the effects of lowpressure carbon dioxide pneumoperitoneum on regional cerebral oxygen saturation and cerebral blood flow. During insufflation, an increase was reported in $\mathrm{EtCO}_{2}$ and $\mathrm{PaCO}_{2}$ levels; they additionally noted that their NIRS value increased by $15.7 \pm 8.8 \%$. This increase did not result from a reduction of cerebral oxygen metabolism during carbon dioxide insufflation, but an increase in cerebral blood flow due to rising carbon dioxide levels.

Hypercarbia results in cerebral vasodilation and increases the cerebral blood flow, a phenomenon which is defined $\mathrm{CO}_{2}$ cerebrovascular reactivity. Evidence from positron emission tomography studies indicates that the cerebral blood volume changes seen during hypercapnia and hypocapnia are primarily caused by arterial volume changes ${ }^{22}$. Hypercapnia studies with NIRS measurement have been carried out in healty volunteers to characterize brain tissue oxygenation and blood flow changes ${ }^{23}$.

In 2012 Quarti et al. ${ }^{24}$ reported a study in 90 pediatric patients with congenital heart disease requiring external carbon dioxide support during cardiopulmonary bypass application to correct carbon dioxide hypocarbia. The authors assessed NIRS and $\mathrm{PaCO}_{2}$ in 3 phases, namely before, during, and after the infusion. After the addition of carbon dioxide, NIRS rose to 63.4 from 52.9; and it decreased to 55.8 by stopping the application. Meanwhile, $\mathrm{PaCO}_{2}$ increased to $40.6 \mathrm{mmHg}$ from $31.3 \mathrm{mmHg}$ and decreased to $34.4 \mathrm{mmHg}$ by stopping application. We also found significant correlations between NIRS and $\mathrm{PaCO}_{2}, \mathrm{PaCO}_{2}$ and $\mathrm{EtCO}_{2}(\mathrm{r}=0.571, \mathrm{p}$ $<0.001)$. A significant and positive correlation existed between NIRS and $\mathrm{EtCO}_{2}(\mathrm{r}=0.479$, $\mathrm{p}<0.001)$.

Hypocapnia induces cerebral vasoconstriction and decreases CBF. We also found lower NIRS level in hypocarbia compared to hypercarbia $(\mathrm{p}<0.001)$.

The limitations of our study included the disproportional number of samples relative to the number of patients, and the lack of the consideration given to the effects of changes in the oxygenation index while assessing the correlation between $\mathrm{PaCO}_{2}$, EtCO 2 and NIRS. Another limitation was a wide age distribution (4-193 months) of our patients. As is known, physiological dead space may show a mild increases with aging, which may have partly affected our results.

The results of the present study suggest that NIRS values of above 80 should alert clinicians for hypercapnia associated with increased cerebral blood flow.

\section{REFERENCES}

1. Fan JL, Burgees KR, Basnyat R, Thomas KN, Ogoh S, Ainslie PN. Influence of indomethacin on ventilatory and cerebrovascular responsiveness to $\mathrm{CO}_{2}$ and breathing stability: the influence of $\mathrm{pCO}_{2}$ gradients. Am J Physiol Regul Integr Comp Physiol 2010; 298: 1648-1658.

2. Hagen EW, Sadek-Badawi M, Carlton DP, Palta M. Permissive hypercapnia and risk for brain injury and developmental impairment. Pediatrics 2008; 122: e583-e589.

3. Vorstrup S, Andersen A, Juhler M, Brun B, Boysen G. Hemodilution increases cerebral blood flow in acute ischemic stroke. Stroke 1989; 20: 884-889.

4. Kacmarek RM, Hickling KG. Permissive hypercapnia. Respir Care 1993; 38: 373-387.

5. Doerr $\mathrm{CH}$, Gajic O, Berrios JC, et al. Hypercapnic acidosis impairs plasma membrane wound releasing in ventilator-injured lungs. Am J Respir Crit Care Med 2005; 171: 1371-1377. 
6. Feihl F, Perret C. Permissive hypercapnia. How permissive should we be? Am J Respir Crit Care Med 1994; 150: 1722-1737.

7. Tateyama T, Asada M, Suzuki H, et al. Effects of $10 \%$ carbon dioxide on regional myocardial tissue oxygen tension and myocardial metabolism. Masui 1994; 43: 59-63.

8. Wu CH, Chou HC, Hsieh WS, et al. Good estimation of arterial carbon dioxide monitoring in neonatal intensive care unit. Pediatr Pulmonol 2003; 35: 292-295.

9. Drayna PG, Abramo TJ, Estrada C. Near infrared spectroscopy in the critical setting. Ped Emerg Care 2011; 27: 432-439.

10. Grahanayem NS, Wernovsky G, Hoffman GM. Near infrared spectroscopy as a hemodynamic monitor in critical illness. Pediatr Crit Care Med 2011; 12: 27-32.

11. Orliaguet GA. Cerebral monitoring in children. Paediatr Anaesth 2004; 14: 407-411.

12. Ward KR, Yealy DM. End-tidal carbon dioxide monitoring in emergency medicine, Part 2: Clinical applications. Acad Emerg Med 1998; 5: 637-646.

13. Bhende MS. Capnography in the pediatric emergency department. Pediatr Emerg Care 1999; 15: 64-69.

14. Rozycki HJ, Sysyn GD, Marshall MK, Malloy R, Wiswell TE. Mainstream end-tidal carbon dioxide monitoring in the neonatal intensive care unit. Pediatrics 1998; 101: 648-653.

15. Bhat YR, Abhisbek N. Mainstream end-tidal carbon dioxide moniyoring in ventilated neonates. Singapore Med J 2008; 49: 199-203.

16. Tingay DG, Stewart MJ, Morley CJ. Monitoring of end tidal carbon dioxide and transcutaneous carbon dioxide during neonatal transport. Arch Dis Child Fetal Neonatal Ed 2005; 90: 523-526.
17. Mcdonalds MJ, Montgomery VL, Cerrito PB, Parrish CJ, Boland KA, Sullivan JE. Comparison of end-tidal CO2 and $\mathrm{PaCO} 2$ in children receiving mechanical ventilation. Pediatr Crit Care Med 2002; 3: 244-249.

18. Razi E, Moosavi GA, Omidi K, Saebi AK, Razi A Correlation of end-tidal carbon dioxide with arterial carbon dioxide in mechanically ventilated patients. Arch Trauma Res 2012; 1: 58-62.

19. Mehta H, Kashyap R, Trivedi S. Correlation of end tidal and arterial carbon dioxide levels in critically Ill neonates and children. Indian J Crit Care Med 2014; 18: $348-353$.

20. Bhat YR, Abhisnek N. Mainstream and-tidal carbondioxide monitoring in ventilated neonates. Singapore Med J 2008; 49: 199-203.

21. De Waal EEC, Jaap W, Kruitwagen CL, Kalkman CJ. The effects of low-pressure carbon dioxide pneumoperitoneum on cerebral oxygenation and cerebral blood volume in children. Anesth Analg 2002; 94: 500-505.

22. Ito $\mathrm{H}$, Ibaraki $\mathrm{M}$, Kanno I, et al. Changes in the arterial fraction of cerebral blood volume during hypercapnia and hypocapnia measured by positron emission tomography. J Cereb Blood Flow Metab 2005; 25: 852-857.

23. Tisdall M, Taylor C, Tachtsidis I, et al. The effect on cerebral tissue oxygenation index of changes in the concentrations of inspired oxygen and end-tidal carbon dioxide in healthy adult volunteers. Anesth Analg 2009; 109: 906-913.

24. Quarti A, Nardone S, Manfrini F, et al. Effect of the adjunct of carbon dioxide during cardiopulmonary bypass on cerebral oxygenation. Perfusion 2012; 28: 152-155. 